\title{
Mast Cell Profile in Benign and Malignant Prostatic Lesions
}

\author{
Bismay Das ${ }^{1 *}$ and Sumanth D. ${ }^{2}$ \\ ${ }^{1}$ Dept of Pathology, AIIMS, Bhubaneshwar, India \\ ${ }^{2}$ Dept of Pathology ,FMMC, Mangalore, India
}

\begin{abstract}
Introduction: Mast cells have an important role in innate and adaptive immunity. There role in tumour pathology is under investigation due to studies linking them to angiogenesis, tissue remodeling and stromal immunomodulation. Reports suggest that they can exert both pro or anti tumour effects. The role of mast cells may be influenced by its location in the lesion. In the present study, the number and distribution of mast cells in both benign and malignant prostatic lesions were recorded.

Methodology: Fifty seven patients of benign prostatic hyperplasia (BPH) and 43 patients of adenocarcinoma (Ca) were the subjects of the study. Inflammatory conditions of prostate like prostatitis and other malignancies of prostate like sarcoma, transitional cell carcinoma etc were excluded from the study. This was a descriptive study with purposive sampling.

Histological diagnosis was made by examining sections stained with Haematoxylin and Eosin. Additional sections from the same block were stained for mast cells using Giemsa stains as per standard protocol. Mast cell count was done in minimum 6 random high power microscopy field in four different regions viz., intraglandular, periglandular, stromal and perivascular regions for BPH and intratumoral, peritumoral, stromal and perivascular regions for $\mathrm{Ca}$. Results were analysed statistically.

Results: BPH cases showed significantly higher number of mast cells in stromal as well as periglandular areas followed by perivascular area. Only few mast cells were observed in intraglandular area. Similar was the observations in adenocarcinoma cases where the maximum number of mast cells were concentrated in the stromal and perilesional area. The number of mast cells in stroma of BPH was higher as compared to that of adenocarcinoma. In rest of the areas, the numbers were comparable.

Conclusion: This study showed no remarkable difference in the number and distribution of mast cells in benign and malignant prostatic lesions. There is paucity of such studies in the literature and the possible utility of mast cell count to differentiate malignant from benign and atypical conditions needs further evaluation.
\end{abstract}

Keywords: Mast Cells, Benign Prostatic Hyperplasia, Adenocarcinoma

\section{Introduction}

Mast cells play an important role in innate and adaptive immunity. ${ }^{[1]}$ Mast cells are located in almost all organs but due to their role in immune mechanism they are localized mainly in the host and environment interfaces like skin, airways, gastrointestinal and urogenital tracts. ${ }^{[2]}$ Once activated mast cells release preformed and newly synthesized mediators including cytokines and chemokines. Many studies have shown that mast cells infiltrate solid tumors. ${ }^{[3]}$ Prostate cancer has been the centre of many such researches. ${ }^{[4,5]}$ Some studies also investigated the role of inflammation in tumourigenesis. ${ }^{[6]}$

Mast cell role in the tumor biology is still controversial as some authors opine that mast cells have a pro-tumorigenic role, ${ }^{[7]}$ and mast cell targeting hampers growth of prostate adenocarcinomas, ${ }^{[8]}$ while others are of the opinion that mast cells have an anti-tumorigenic role. ${ }^{[9]}$ Another school of thought indicated that role of mast cell in tumor depends on the location of mast cell. ${ }^{[9]}$ Authors have also tried to correlate the mast cell numbers with density of micro vessels. ${ }^{[10]}$

With Prostate cancer being second most common cancer in males and incidence of castration resistant prostate carcinoma (CRPC) high, ${ }^{[11]}$ a novel method of treatment of prostate carcinoma will prove to be indispensible. Mast cell provides one such target but the challenge is to ascertain the actual role of mast cells, whether this role is influenced by its location in and around tumor tissue and the influence of tumor microenvironment. The present work aimed to study mast cell distribution and count in benign and malignant prostatic lesions.

\section{Materials \& Methods}

Fifty seven patients of benign prostatic hyperplasia (BPH) and 43 patients of adenocarcinoma (Ca) were the subjects of the study. Inflammatory conditions of prostate like prostatitis and other malignancies of prostate like 
sarcoma, transitional cell carcinoma etc were excluded from the study. This was a descriptive study with purposive sampling.

The prostatic specimens including prostatic biopsies, transurethral resection of prostate(TURP) chips and excision biopsies of prostate were examined histopathologically.

The specimens collected were fixed in $10 \%$ formalin for 12 to 24 hours before processing in an automatic sample processor after grossing. Sections of $4 \mu \mathrm{m}$ thick were cut with a rotary microtome. Histological diagnosis was made by examining sections stained with Haematoxylin and Eosin.Additional sections from the same block were stained for mast cells using Giemsa stains as per standard protocol. Mast cell count was done in minimum 6 random high power microscopy field in four different regions viz., intraglandular, periglandular, stromal and perivascular regions for $\mathrm{BPH}$ and intratumoral, peritumoral, stromal and perivascular regions for $\mathrm{Ca}$.

All the data was entered into Microsoft Excel 2010 spread sheet and analysed using SSPS software version 13.0. Descriptive statistics were derived using frequency, percentage, mean, standard deviation. Student $t$ test and ANOVA test were used to test the significance i.e. nominal significance at $p$ value $\leq 0.05$ levels, and the $p$ value $>0.05$ was not significant.

\section{Results}

Prostatic specimens of 100 patients were examined histopathologically for the distribution of mast cells in different regions. Fifty seven patients were of BPH while rest 43 were cases of Adenocarcinoma. The mean age of Adenocarcinoma group (71.21 \pm 8.9 years) was significantly higher $(\mathrm{P}=0.004)$ as compared to that of BPH group ( $66.09 \pm 8.42$ years). The number of mast cells according to the different regions examined in BPH and Adenocarcinoma groups is depicted in Table 1, Figure 1 $\& 2$.

\section{Statistical comparison}

$\begin{array}{lll}\mathrm{A} / \mathrm{B} & \mathrm{P}<0.001 & \mathrm{P}<0.001 \\ \mathrm{~A} / \mathrm{C} & \mathrm{P}<0.001 & \mathrm{P}<0.001 \\ \mathrm{~A} / \mathrm{D} & \mathrm{P}<0.001 & \mathrm{P}<0.001 \\ \mathrm{~B} / \mathrm{C} & \mathrm{P}=0.022 & \mathrm{P}=0.998 \\ \mathrm{~B} / \mathrm{D} & \mathrm{P}=0.002 & \mathrm{P}=0.002 \\ \mathrm{C} / \mathrm{D} & \mathrm{P}<0.001 & \mathrm{P}<0.001\end{array}$

NS-Non significant

In $\mathrm{BPH}$ group, the maximum numbers of mast cells were concentrated in the stromal region followed by periglandularand perivascular region. Only few mast cells were observed in the intraglandular regions. The differences are statistically significant. Almost similar was the observations for the Adenocarcinoma group except that the mean number of mast cells in stromal region was comparable to that of perilesional region

When both groups were compared, only stromal region of Adenocarcinoma group had significantly lower mean levels of mast cells as compared to BPH group $(\mathrm{P}=0.039)$. However, the mean mast cell numbers in rest the three regions as well as total numbers of mast cells were comparable in two groups.

\section{Discussion}

Prostatic specimens of 57 cases of BPH and 43 cases of Adenocarcinoma were examined histopathologically for the distribution of mast cells in different regions. In both groups, maximum number of mast cells were concentrated in the stromal region followed by periglandular/perilesional, perivascular and intraglandular/intralesional region in that order. There was increased number of mast cells in stroma of BPH in comparison to Adenocarcinoma.

Table 1: Number of mast cells (Mean \pm 1 SD) according to the regions in BPH and Adenocarcinoma cases.

\begin{tabular}{|l|l|l|l|}
\hline Region & $\begin{array}{l}\text { BPH } \\
(\mathrm{N}=57)\end{array}$ & $\begin{array}{l}\text { Adenocarcinoma } \\
(\mathrm{N}=43)\end{array}$ & P-Value \\
\hline A.Intraglandular/ Intralesional & $0.05 \pm 0.294$ & $0.14 \pm 0.639$ & $0.366(\mathrm{NS})$ \\
\hline B. Periglandular/ Perilesional & $11.0 \pm 9.532$ & $11.23 \pm 8.842$ & $0.901(\mathrm{NS})$ \\
\hline C. Stromal & $14.75 \pm 9.232$ & $11.42 \pm 6.744$ & $0.039(\mathrm{NS})$ \\
\hline D. Perivascular & $6.33 \pm 4.133$ & $6.55 \pm 4.871$ & $0.801(\mathrm{NS})$ \\
\hline Total & $\mathbf{8 . 0 3} \pm \mathbf{7 . 5 8 1}$ & $\mathbf{7 . 3 3} \pm \mathbf{8 . 8 2 8}$ & $\mathbf{0 . 6 7 2}$ (NS) \\
\hline
\end{tabular}




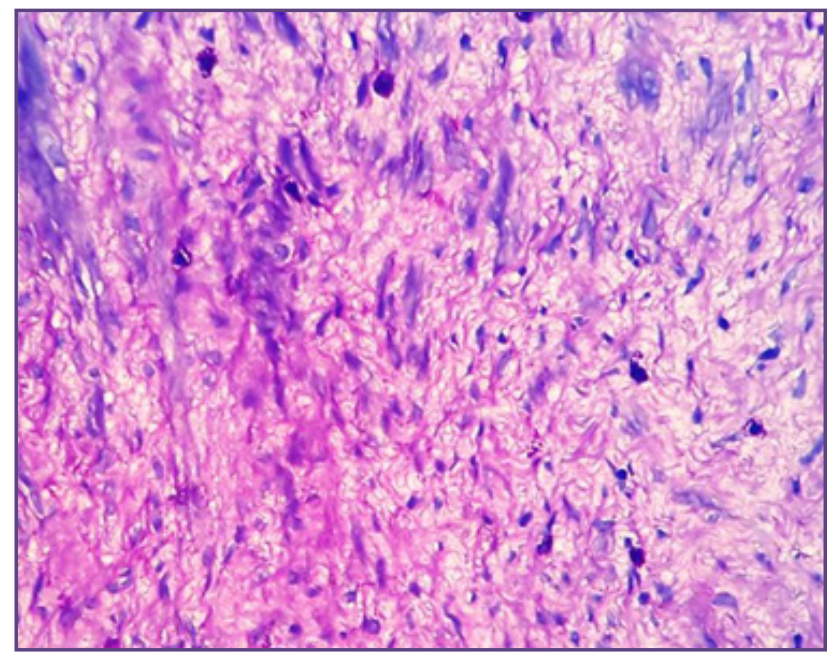

Fig. 1: Photomicrograph showing stromal mast cells in BPH (400 x , Giemsa stain).

Similar to our study, Amir et al (1998) observed significantly higher number of mast cells in the fibromuscular stroma when compared to the glandular areas in nodular hyperplasia $(\mathrm{p}<.05)$. The authors also reported absence or a low count in tumoral region of Adenocarcinoma. ${ }^{[12]}$

In contrast to above observations, Rakshith and Kumar (2016) studied the mast cells number in 75 cases of benign prostatic hyperplasia and 25 cases of prostatic adenocarcinoma. The authors observed a significant increase in the number of mast cells in patients with adenocarcinoma as compared to benign prostatic hyperplasia and postulated a stimulating role of mast cells in the progression of cancer. ${ }^{[13]}$

Aydin et al (2002) investigated the utility of mast cells in evaluating benign and malignant prostate lesion. Mast cells were more frequently observed in the fibromuscular area than in the adenomatous area in BPH cases. There was a significant difference between mast cell density in intralesional and perilesional region. ${ }^{[14]}$

Gupta et al found either a small number of mast cells or they were completely absent both in prostatic tumoral and stromal area compared to benign nodular hyperplasia or normal tissue. ${ }^{[4]}$

Globa et al (2014) observed mast cells near the basal membrane of glandular epithelium in normal prostate. Mast Cells were predominantly located in the periglandular areas, close to blood vessels of prostate stroma. The distribution of mast cells in BPH was similar to that of normal prostate tissue. MCs were found along the blood vessel grouped in small cell clusters. The density of MCs in BPH was in the normal range, maintaining a higher distribution in periglandular areas. In Adenocarcinoma cases, mast cell

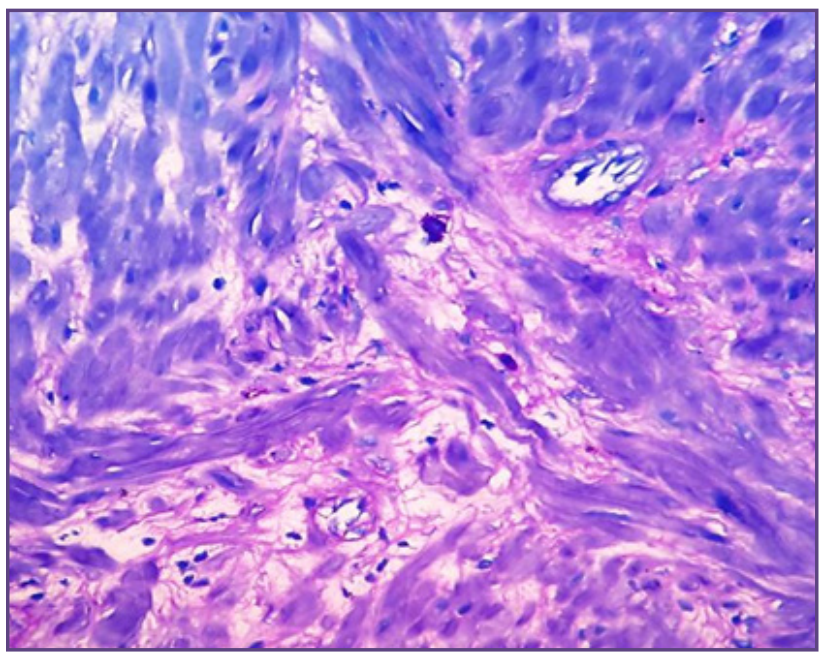

Fig. 2: Photomicrograph showing stromal mast cells in Adenocarcinoma (400 x , Giemsa stain).

density decreased in the intratumoral area as compared to peritumoral areas. The MCs were arranged around the epithelial tumor cell area and rarely intraepithelially ${ }^{[2]}$

Johansson et al (2010) found that in both non-malignant and malignant human prostate tissue, mast cells were found principally in the stroma. In prostate tumors, only a few mast cells were detected in the epithelial compartment. They also found that the mean number of mast cells in the non-malignant stroma was significantly higher than in the tumor stroma. ${ }^{[15]}$

\section{Conclusion}

This study showed no remarkable difference in the number and distribution of mast cells in benign and malignant prostatic lesions. However, there is paucity of such studies in the literature and the possible utility of mast cell count to differentiate malignant from benign and atypical conditions needs further evaluation.

\section{References}

1. Barret KE, Ganong WF. Immunity, infection and inflammation In : Ganong's Review of medical physiology. New York: McGraw-Hill Medical: 2005.p.63-78.

2. Globa T, Şaptefrţi L, Ceauşu RA, Gaje P, Cimpean AM, Raica M. Mast cell phenotype in benign and malignant tumors of the prostate. Pol JPathol 2014; 2:147-153.

3. Theoharides TC, Conti P. Mast cells: the Jekyll and Hyde of tumor growth. Trends Immunol 2004; 25:235-241.

4. Gupta RK. Mast cell variations in prostate and urinary bladder. Arch Pathol1970; 89:302-305.

5. Sari A, Serel TA, Çandir Ö, Öztürk A, Kosar A. Mast cell variations in tumour tissue and with histopathological grading in specimens of prostatic adenocarcinoma. BJU Int 1999; 84: 851-853 
6. Strasner A, Karin M. Immune infiltration and prostate cancer. Front Oncol 2015; 5:128.

7. Crivellato E, Nico B, Ribatti D. Mast cell contribution to tumor angiogenesis: a clinical approach.Eur Cytokine Netw 2009; 20:197-206.

8. Pittoni P, Tripodo C, Piconese S, Mauri G, Parenza M, Rigoni A et al. Mast cell targeting hampers prostate adenocarcinoma development but promotes the occurrence of highly malignant neuroendocrine cancers. Cancer Res 2011; 71: 5987-5997.

9. Conti P, Castellani ML, Kempuraj D, Salani V, Vecchiet J, Tete S, Mastrangelo F, Parrella A, Lutiis MAD, Tangen M, Theoharides TC. Role of mast cells in tumour growth. Ann Clin Lab Sci 2007; 34(4): 315-21.

10. Stawerski P, Wagrowska-Danilewicz M, StasikowskaKanicka O, Tuka E, Danilewicz M. Augmented mast cell infiltration and microvessel density in prostate cancer. Contemp Oncol 2013; 17:378.
11. Li L, Dang Q, Xie H, Yang Z, He L, Liang L, Song W, Yeh S et al. Infiltrating mast cells enhance prostate cancer invasion via altering LncRNA-HOTAIR/PRC2-androgen receptor (AR)-MMP9 signals and increased stem/progenitor cell population.Oncotarget 2015;6:14179-90.

12. Amir T, Pai RR, Raghuveer CV. Mast Cell Profile in Prostatic Lesions. Indian J Med Sci 1998; 52:507-13.

13. Rakshith V, Kumar ML. Study of mast cells in prostate lesions: Adenocarcinoma compared with hyperplasia. Clin Cancer Investig J 2016; 5:121-5

14. Aydin O, Dusmez D, Cinel L, Doruk E, Kanik A. Immunohistological analysis of mast cell numbers in the intratumoral and peritumoral regions of prostate carcinoma compared to benign prostatic hyperplasia. Pathol Res Pract.2002; 198: 267-71.

15. Johansson A, Rudolfsson S, Hammarsten P, Halin S, Pietras $\mathrm{K}$, Jones $\mathrm{J}$ et al. Mast cells are novel independent prognostic markers in prostate cancer and represent a target for therapy. Am J Pathol 2010; 177: 1031-1041.

*Corresponding author:

Dr Bismay Das, Department of Pathology, All India Institute of Medical Sciences, Bhubaneswar, Odisha

Email: bismaydas@yahoo.com

Financial or other Competing Interests: None. 